ORIGINAL ARTICLE

\title{
Psychiatric symptoms and disorders in adolescents with low birth weight
}

\author{
M S Indredavik, T Vik, S Heyerdahl, S Kulseng, P Fayers, A-M Brubakk
}

Arch Dis Child Fetal Neonatal Ed 2004;89:F445-F450. doi: 10.1136/adc.2003.038943

See end of article for
authors' affiliations
$\ldots \ldots \ldots \ldots \ldots \ldots \ldots \ldots . \ldots . \ldots$.
Correspondence to:
Dr Indredavik, Department
of Neuroscience,
Medisinsk teknisk
forskningssenter, NO-
7489 Trondheim, Norway;
marit.s.indredavik@
medisin.nntnu.no
Accepted
6 November 2003

\begin{abstract}
Objective: To evaluate the prevalence of psychiatric symptoms and disorders associated with low birth weight.

Design/study groups: A population based follow up study of 56 very low birthweight (VLBW: birth weight $\leqslant 1500 \mathrm{~g}$ ), 60 term small for gestational age (SGA: birth weight $<10$ th centile), and 83 term control (birth weight $\geqslant 10$ th centile) children at 14 years of age.

Outcome measures: Schedule for affective disorders and schizophrenia for school aged children, attention deficit/hyperactivity disorder (ADHD) rating scale IV, autism spectrum screening questionnaire, and children's global assessment scale.

Results: VLBW adolescents had a higher prevalence of psychiatric symptoms (46\%) than controls (13\%) (odds ratio (OR) $5.7,95 \%$ confidence interval (CI) 2.5 to 13.0 ) and more psychiatric disorders (25\%) than controls (7\%) (OR $4.3,95 \% \mathrm{Cl} 1.5$ to 12.0$)$, especially anxiety disorders. Although $25 \%$ of the VLBW adolescents had attention problems, ADHD was diagnosed in only 7\%. Four VLBW adolescents had symptoms of Asperger's disorder, and the VLBW group had a higher sum score than controls on the autism spectrum screening questionnaire. Although more SGA adolescents had psychiatric symptoms than controls $(23 \% \vee 13 \%)$, the difference was not statistically significant. Results remained essentially the same when adolescents with low estimated intelligence quotient were excluded, and persisted after possible psychosocial confounders had been controlled for.

Conclusion: VLBW, but not SGA adolescents, have a high risk of developing psychiatric symptoms and disorders by the age of 14, especially attention deficit, anxiety symptoms, and relational problems.
\end{abstract}

$\mathrm{F}$ ollow up studies of very low birthweight (VLBW) children have documented increased prevalence of neurodevelopmental disabilities and cognitive deficits. ${ }^{1-3}$ There has been a growing awareness of psychiatric problems..$^{4-7}$ The most consistent finding is an increased risk of attention deficit/hyperactivity disorder (ADHD), especially the inattentive type. ${ }^{3689}$ Anxiety disorders, depression, and thought problems may also occur. ${ }^{67}$

For children born small for gestational age (SGA) at term, the outcome is less clear, especially when it comes to social and emotional development. ${ }^{6}{ }^{10-14}$ VLBW and term SGA infants differ in biological basis and vulnerability, hence the long term outcome may vary. Most studies are performed in childhood using questionnaires. ${ }^{3}$ Although there are some follow up reports in adolescence, our knowledge on psychiatric disorders in this age group is limited, and few have used psychiatric interview as a diagnostic tool. ${ }^{4} 5715-20$ By using in depth psychiatric assessment, we wanted to evaluate whether the prevalence of psychiatric symptoms and disorders is higher in VLBW and SGA adolescents than in adolescents with normal birth weight, and describe the characteristics of psychiatric symptoms and disorders in these groups.

\section{MATERIAL AND METHODS \\ Study design}

This study is a population based follow up at 14 years of age of two groups of adolescents with low birth weight (VLBW and term SGA) compared with a control group of normal birth weight. The VLBW children were admitted to the neonatal intensive care unit at the University Hospital in Trondheim (the referral hospital) in 1986-1988. Children born in 1988 were assessed thoroughly at 1 and 6 years of age. ${ }^{21-23}$ The SGA and control children were born to mothers living in the Trondheim region. They were enrolled before week 20 of pregnancy in a multicentre study between January 1986 and March 1988. ${ }^{24}{ }^{25}$ A 10\% random sample of women (with one or two previous pregnancies) was selected for follow up during pregnancy. At birth, all the children born to mothers in the random sample and all the SGA children were included for follow up. ${ }^{26}$ The present study was carried out between November 2000 and October 2002, and included a psychiatric assessment, an evaluation of cognitive and motor abilities, and a neuropaediatric examination.

\section{Study population \\ VLBW adolescents}

VLBW was defined as a birth weight $\leqslant 1500$ g. Ninety nine children were admitted to the neonatal intensive care unit in 1986-1988. Of these, 23 died, one child with trisomy 21 was excluded, and six had moved. Of the remaining 69, 13 did not consent to participate at follow up. Thus $56(81 \%)$ were examined (30 boys, 26 girls). Twelve had a birth weight $\leqslant 1000 \mathrm{~g}$. Ten participants were twins, of whom six were in twin pairs.

\section{SGA adolescents}

Of 1200 eligible women, 104 (9\%) gave birth to an SGA child, defined by a birth weight $<10$ th centile of all infants in the multicentre study, adjusted for gestational age, sex, and parity. ${ }^{25}$ At follow up, 12 had moved. Of the remaining 92, 32

\footnotetext{
Abbreviations: $A D H D$, attention deficit/hyperactivity disorder; $A S S Q$, autism spectrum screening questionnaire; CGAS, children's global assessment scale; DSM-IV, Diagnostic and statistical manual of mental disorders, fourth edition; $1 \mathrm{Q}_{\text {est, }}$ estimate of intelligence quotient; $S G A$, small for gestational age; VLBW, very low birthweight
} 


\section{What is already known on this topic}

- VLBW children have increased risk of emotional and behavioural problems, especially attention problems

- Psychiatric outcome for term SGA children is less clear

\section{What this study adds}

- Prevalence of psychiatric symptoms and disorders in VLBW and term SGA adolescents, based on in depth psychiatric assessment

- Description of psychiatric symptoms and disorders in these groups, highlighting:

- Attention deficit symptoms were common in VLBW adolescents, however, only a minority had ADHD

- Deficits in social skills and autistic spectrum symptoms occurred in the VLBW group

- Psychiatric problems affected the overall functioning of both VLBW and SGA adolescents

did not consent, leaving 60 (65\%) for assessment (28 boys, 32 girls).

\section{Control adolescents}

The control group comprised 120 children with a birth weight $\geqslant 10$ th centile for gestational age, born at term to mothers in the $10 \%$ random sample. At follow up, 10 had moved. Of the remaining 110, 27 did not consent, leaving 83 (76\%) who participated ( 35 boys, 48 girls).

\section{Non-participants}

There were no differences in mothers' age at childbirth, duration of pregnancy, or the infants' birth weight, body length, and head circumference between those who participated and those who did not consent in any of the groups.

\section{Methods}

Psychiatric assessment

Psychiatric symptoms and disorders were diagnosed using the semistructured interview Schedule for affective disorders and schizophrenia for school aged children (KSADS). ${ }^{27}{ }^{28}$ This interview is performed separately with parent and adolescent. It consists of a screening part and supplementary diagnostic interviews. Conclusions are drawn according to the Diagnostic and statistical manual of mental disorders, fourth edition (DSMIV). ${ }^{29}$ The interviewer differentiates between diagnosis, symptoms $\geqslant 75 \%$ level of diagnostic criteria, or neither.

Of the 199 adolescents, the first author assessed 171, and another child psychiatrist carried out 28 interviews. The first 27 interviews with adolescents were videotaped and scored to test interrater reliability. The intraclass correlation coefficient was 0.91 for all symptoms, 0.86 for anxiety symptoms, and 0.86 for ADHD symptoms. A third senior child psychiatrist, blinded to the first evaluation, performed a second diagnostic assessment based on the written interviews. Subsequently, diagnostic consensus was obtained. The child psychiatrists were blinded to birth weight status.

The interviewer scored the adolescents' overall functioning on the children's global assessment scale (CGAS). ${ }^{30}$ This scale ranges from 1 to 100 , divided into 10 main categories. A score above 80 denotes good functioning.

The psychiatric interview was supplemented with the autism spectrum screening questionnaire (ASSQ), ${ }^{31}$ as part of the parents' interview, and the teachers' report on ADHD rating scale IV. ${ }^{32}{ }^{33}$ Parents stated their own mental health on symptom checklist-90-R (SCL-90-R), and we used the global severity index as a single summary measure of psychological distress. ${ }^{34}$

\section{Evaluation of cognitive abilities}

An estimate of intelligence quotient $\left(\mathrm{IQ}_{\mathrm{est}}\right)$ was calculated using four of 10 subscales of Wechsler intelligence scales (WISC-III) $^{35}$ : vocabulary, arithmetic, block design and picture arrangement. ${ }^{36}$ We defined "low IQest" as below 2 SDs of the control group mean value. Data were analysed both including and excluding children with low IQest.

\section{Socioeconomic status}

Socioeconomic status was calculated according to Hollingshead's two factor index of social position, based on a combination of parents' education and occupation. ${ }^{37}$

\section{Ethics}

The regional committee for medical research ethics approved the study protocol. Written informed consent was obtained from adolescents and parents.

\section{Statistical analysis}

SPSS 11.5.1 was used for data analysis. Three group comparisons were made using one way analysis of variance for variables with a normal distribution and Kruskal-Wallis for ordinal data. If a difference was found between groups $(\mathrm{p}<0.05)$, two group comparisons were made using Scheffe's post hoc test for normally distributed variables and the Mann-Whitney $U$ test for variables with a nonnormal distribution. ${ }^{38}$ Differences in proportions between groups were analysed by the $\chi^{2}$ test. Odds ratios (OR) with $95 \%$ confidence interval $(95 \% \mathrm{CI})$ were calculated as an estimate of the relative risk that a child with low birth weight had psychiatric symptoms and disorders, compared with the control group. To control for possible confounders, we used binary logistic regression ${ }^{38}$ to calculate adjusted OR, first in a bivariate analysis, followed by a multivariate analysis (backward stepwise) for covariates altering the unadjusted OR $>10 \%$.

\section{RESULTS}

\section{Group characteristics}

Table 1 shows family and child characteristics. There were no significant differences between groups with regard to mothers' or fathers' education, socioeconomic status, monthly income, or maternal or paternal mental health. Likewise, there were no sex differences between the groups. Of the 56 VLBW adolescents, seven (13\%) were living in single parent families, compared with five $(8 \%)$ in the SGA and $15(18 \%)$ in the control group (ns).

Ten (18\%) VLBW adolescents had low IQ $_{\text {est }}$ compared with four $(7 \%)$ SGA and three (4\%) controls. Cerebral palsy was diagnosed in six (11\%) VLBW (four diplegia, one hemiplegia, one quadriplegia), and one SGA adolescent (diplegia). Four of the VLBW and the one SGA with cerebral palsy had low $\mathrm{IQ}_{\text {est }}$. Two VLBW and one control adolescent had epilepsy. There were no major visual or hearing impairments.

\section{Psychiatric assessment by semistructured interview (KSADS)}

Of the 56 VLBW adolescents, 26 (46\%) had emotional or behavioural problems $\geqslant 75 \%$ of diagnostic criteria, compared with 11 of 83 (13\%) controls (OR 5.7, 95\%CI 2.5 to 13.0) (table 2). The most common symptoms among VLBW adolescents were attention deficit (OR 6.6, 95\%CI 2.0 to $21.3 v$ controls) and anxiety (OR 3.5, 95\%CI 1.2 to $10.0 v$ 
Table 1 Family and child characteristics in two groups of low birthweight adolescents compared with a control group at 14 years of age

\begin{tabular}{|c|c|c|c|}
\hline & $\begin{array}{l}\text { VLBW } \\
(\mathrm{n}=56)\end{array}$ & $\begin{array}{l}\text { SGA } \\
(n=60)\end{array}$ & $\begin{array}{l}\text { Control } \\
(n=83)\end{array}$ \\
\hline \multicolumn{4}{|l|}{ Family characteristics } \\
\hline \multicolumn{4}{|l|}{ Maternal } \\
\hline Age (years) & $42.3(5.0)$ & $42.1(3.6)^{*}$ & $44.0(4.5)$ \\
\hline Education (years) & $13.5(3.4)$ & $12.9(3.1)$ & $14.2(2.9)$ \\
\hline Mental health $\dagger$ & $0.26(0.22)$ & $0.27(0.26)$ & $0.28(0.23)$ \\
\hline \multicolumn{4}{|l|}{ Paternal } \\
\hline Age (years) & $45.7(5.9)$ & $44.4(3.6)$ & $46.0(4.8)$ \\
\hline Education (years) & $13.1(3.7)$ & $13.4(2.8)$ & $14.1(3.1)$ \\
\hline Mental health $\ddagger$ & $0.31(0.42)$ & $0.17(0.17)$ & $0.18(0.17)$ \\
\hline Socioeconomic status & $3.3(1.3)$ & $3.4(1.3)$ & $3.8(1.1)$ \\
\hline Monthly income (1000 NOK) & $31.8(10.9)$ & $30.9(9.9)$ & $29.5(9.9)$ \\
\hline \multicolumn{4}{|c|}{ Child characteristics } \\
\hline Birth weight (g) & $1174(233) \S$ & $2921(211) \S$ & $3691(459)$ \\
\hline Gestational age (weeks) & $28.8(2.7) \S$ & $39.5(1.1)$ & $39.6(1.2)$ \\
\hline Assessment age (years) & $14.1(0.3)$ & $14.2(0.3)$ & $14.2(0.3)$ \\
\hline \multicolumn{4}{|c|}{$\begin{array}{l}\text { Values are mean (SD). } \\
\text { " } p<0.05 v \text { controls. Three group comparisons performed with analysis } \\
\text { of variance and Scheffe's post hoc test for parametric data, and Kruskal- } \\
\text { Wallis and Mann-Whitney U test for non-parametric data. } \\
\text { †Mothers' mean global severity index on symptom checklist- } 90-\mathrm{R}^{34} \text { was } \\
\text { missing for six VLBW, one SGA, and nine control adolescents. } \\
\text { fFathers' mean global severity index on symptom checklist-90- } \mathrm{R}^{34} \text { was } \\
\text { missing for } 10 \text { VLBW, six SGA, and } 15 \text { control adolescents. } \\
\S \text { These were the selection criteria, and differed by definition versus } \\
\text { controls ( } \mathrm{p} \leqslant 0.001 \text { ). } \\
\text { VLBW, Very low birth weight; SGA, small for gestational age. }\end{array}$} \\
\hline
\end{tabular}

controls). Four VLBW adolescents had symptoms of Asperger's disorder, compared with none in the control group $(\mathrm{p}<0.05)$.

Psychiatric disorders were diagnosed in $14(25 \%)$ VLBW adolescents compared with six (7\%) controls (OR 4.3, 95\%CI 1.5 to 12.0 ) (table 2). Anxiety disorders were most prevalent (OR 4.4, 95\%CI 1.1 to $17.6 v$ controls), whereas four $(7 \%)$ had ADHD compared with one control (ns). One VLBW adolescent had Asperger's disorder. Six of 12 (50\%) with birth weight $\leqslant 1000 \mathrm{~g}$ and eight of $44(18 \%)$ with birth weight $>1000 \mathrm{~g}$ had a psychiatric diagnosis $(\mathrm{p}=0.054)$.

Nine of the 10 VLBW adolescents with low IQest had psychiatric symptoms, and four had a diagnosis (ADHD, Asperger's disorder, anxiety disorders). Of the two VLBW adolescents with cerebral palsy without low IQ est $_{\text {, }}$ one had ADHD.

Although 14 (23\%) SGA adolescents had psychiatric symptoms, and six (10\%) had a psychiatric disorder, this did not differ significantly from controls (table 2).

There were no sex differences in the VLBW and SGA group, whereas in the control group more boys than girls had ADHD symptoms $(\mathrm{p}<0.05)$.

Few had experienced drinking $\geqslant 3$ units of alcohol (two VLBW adolescents, three SGA, five controls) (ns). One adolescent in each group admitted experimenting with other substances (cannabis, amphetamine).

\section{ADHD rating scale IV}

VLBW adolescents had higher mean attention score and total score than controls, without significant difference in hyperactivity score (table 3). Although the SGA group had higher total score than controls, the difference was not significant. Boys had a higher total score than girls in the control $(p<0.01)$ and SGA groups $(p<0.05)$, but not in the VLBW group $(\mathrm{p}=0.30)$ (data not shown).

\section{Autism spectrum screening questionnaire (ASSQ)}

The VLBW group had higher mean sum score than controls (table 3), whereas the SGA group showed a trend towards a higher sum score compared with controls $(p=0.08)$. There were no sex differences. VLBW adolescents had high scores on the items: "Lives somewhat in a world of his/her own with restricted idiosyncratic intellectual interests", "Has a literal understanding of ambiguous and metaphorical language", "Uses language freely but fails to make adjustment to fit social contexts or the needs of different listeners", "Lacks empathy", "Wishes to be sociable but fails to make relationships with peers".

\section{Children's global assessment scale (CGAS)}

VLBW adolescents had lower mean CGAS score than controls (table 3). Scores below 80 were found in 37 of $56(66 \%)$ VLBW, 17 of 83 (21\%) control (OR 7.6, 95\%CI 3.5 to 16.3 ), and 24 of $60(40 \%)$ SGA (OR 2.6, 95\%CI 1.2 to $5.4 v$ controls) adolescents. There were no sex differences in any of the groups.

\section{Excluding adolescents with low $I Q_{\text {est }}$}

When adolescents with low $\mathrm{IQ}_{\text {est }}$ were excluded, the results were essentially unchanged, except that the VLBW group had a reduced prevalence of anxiety symptoms $(p=0.09)$ and disorders $(p=0.07)$ compared with controls.

\section{Multivariate analyses}

With the outcome variable symptoms of any psychiatric disorder $(\geqslant 75 \%$ of diagnostic criteria), logistic regression analysis was run to evaluate the confounding effect of psychosocial factors (table 4). Paternal education and maternal and paternal mental health were the only factors that influenced the increased risk of psychiatric symptoms in the VLBW group more than $10 \%$. When these variables were included in multivariate analysis, the increased risk associated with VLBW was 5.8 (95\%CI 1.9 to 17.4), with maternal mental health as the only variable causing a significant change. Analogously, after multivariate analysis, the risk associated with SGA was 2.9 (95\%CI 1.0 to 8.2$)$, with only paternal mental health causing a significant change.

\section{DISCUSSION}

In this study we found that nearly every other VLBW adolescent had psychiatric symptoms. One in four had a psychiatric diagnosis, anxiety disorders being the most prevalent. Attention deficit problems were acknowledged in every fourth VLBW adolescent, but only a minority fulfilled the diagnostic criteria. Moreover, relational problems and deficits in social skills were common among VLBW adolescents, and some had autistic spectrum symptoms. Although every fifth SGA adolescent had psychiatric symptoms, they did not differ significantly from controls.

The strength of this study is the thoroughness of the psychiatric assessment, using both questionnaires and a semistructured interview, and different sources of information. Even though the VLBW adolescents had widespread emotional or behavioural symptoms, many did not reach the diagnostic level of a psychiatric disorder. However, the CGAS results indicate that the psychiatric problems were affecting the overall functioning in both the VLBW and the SGA group, causing strain for the adolescents and their families.

The psychiatric outcome was significantly worse for the VLBW group, with consistent results across all instruments. This association is unlikely to be due to chance. The lack of statistical significance for the SGA group may be due to the limited sample size.

Of the eligible children, $73 \%$ (199/271) took part in the study. There were no differences in key variables between participants and those who did not consent to participate. It is therefore unlikely that our main results are caused by selection bias. 
Table 2 Psychiatric symptoms and diagnoses according to DSM-IV, based on in depth psychiatric interview, in two groups of low birthweight adolescents compared with a control group at 14 years of age

\begin{tabular}{|c|c|c|c|}
\hline & VLBW $(n=56)$ & SGA $(n=60)$ & Control $(n=83)$ \\
\hline $\begin{array}{l}\text { Symptoms } \geqslant 75 \% \text { of diagnostic criteria } \\
\text { Symptoms any psychiatric disorder } \\
\text { Of these }\end{array}$ & $26(46)^{* * *}$ & $14(23)$ & $11(13)$ \\
\hline Symptoms anxiety disorders & $12(21)^{*}$ & $7(12)$ & $6(7)$ \\
\hline Symptoms depressive disorder & & $3(5)$ & \\
\hline Symptoms ADHD & $14(25)^{* * *}$ & $4(7)$ & $4(5)$ \\
\hline Symptoms conduct disorder & $1(2)$ & $3(5)$ & $3(4)$ \\
\hline Symptoms Asperger's disorder & $4(7)^{*}$ & 0 & 0 \\
\hline Other symptom categories & $5(9)$ & $3(5)$ & $3(4)$ \\
\hline$\geqslant 2$ symptom categories & $9(16)$ & $4(7)$ & $5(6)$ \\
\hline \multicolumn{4}{|l|}{ Diagnostic level } \\
\hline $\begin{array}{l}\text { Any psychiatric disorder } \\
\text { Of these }\end{array}$ & \multicolumn{3}{|c|}{ Of these } \\
\hline Anxiety disorders $\dagger$ & $8(14)^{*}$ & $4(7)$ & $3(4)$ \\
\hline Depressive disorder & $2(4)$ & 0 & 0 \\
\hline ADHD & $4(7)$ & $2(3)$ & $1(1)$ \\
\hline Conduct disorder & 0 & $2(3)$ & $1(1)$ \\
\hline Asperger's disorder & $1(2)$ & 0 & 0 \\
\hline Other disorders $\ddagger$ & $4(7)$ & $1(2)$ & $2(2)$ \\
\hline$\geqslant 2$ diagnoses $\S$ & $5(9)^{*}$ & $2(3)$ & $1(1)$ \\
\hline \multicolumn{4}{|c|}{$\begin{array}{l}\text { Values are number }(\%) . \\
{ }^{*} \mathrm{p}<0.05,{ }^{* *} \mathrm{p}<0.01,{ }^{* * *} \mathrm{p} \leqslant 0.001 v \text { controls. } \chi^{2} \text { test was used to analyse differences in proportions between } \\
\text { groups, with Fisher's exact test when cell number less than five. } \\
\text { †Anxiety disorders: separation anxiety disorder, generalised anxiety disorder, social phobia, or specific phobia. } \\
\text { fOther disorders: adjustment disorder, elimination disorder, post-traumatic stress disorder, stuttering, tic disorder. } \\
\text { None had manic or bipolar, psychotic, or eating disorder. } \\
\text { sComorbid diagnoses: ADHD, adjustment disorder, anxiety disorder, Asperger's disorder, conduct disorder, } \\
\text { depressive disorder, elimination disorder, post-traumatic stress disorder, stuttering. } \\
\text { DSM-IV, Diagnostic and statistical manual of mental disorder; fourth edition }{ }^{29} ; \mathrm{VLBW,} \text {, very low birth weight; SGA, } \\
\text { small for gestational age; ADHD, attention deficit/hyperactivity disorder. }\end{array}$} \\
\hline
\end{tabular}

The parents of VLBW children knew that their child belonged to a risk group. However, the examiners were blinded, and assessment was based on separate interviews with adolescent and parent, including clinical judgment and teachers' report on ADHD rating scale, making it less likely that the results are caused by information bias.

The VLBW children were classified according to a birth weight $\leqslant 1500 \mathrm{~g}$, and some of them may have been growth retarded in utero. However, they were all born preterm, and we have chosen to treat them as a group in this study. The 10th centile definition of SGA is crude, and may include a certain proportion of normal small infants, whereas some growth retarded infants may have been classified as controls.

Table 3 Results on questionnaires: ADHD rating scale IV, autism spectrum screening questionnaire, and children's global assessment scale in two groups of low birthweight adolescents compared with a control group at 14 years of age

\begin{tabular}{llll}
\hline & $\begin{array}{l}\text { VLBW } \\
(\mathbf{n}=56)\end{array}$ & $\begin{array}{l}\text { SGA } \\
(\mathbf{n}=60)\end{array}$ & $\begin{array}{l}\text { Control } \\
(\mathbf{n}=\mathbf{8 3})\end{array}$ \\
\hline ADHD rating scale IV (teachers' report)† & & \\
Attention score & $7.1(6.0)^{* * *}$ & $5.1(6.4)$ & $3.8(5.9)$ \\
Hyperactivity score & $2.7(4.4)$ & $3.0(5.3)$ & $2.1(4.4)$ \\
Total score & $9.8(9.0)^{* * *}$ & $8.1(10.9)$ & $5.9(10.0)$ \\
ASSQ sum score & $5.5(5.9)^{* * *}$ & $3.0(4.7)$ & $2.0(2.7)$ \\
CGAS score & $72.8(16.5)^{* * *}$ & $82.3(10.8)$ & $85.3(8.2)$ \\
\hline
\end{tabular}

Values are mean (SD).

${ }_{* * *} p<0.001 v$ controls. Three group comparisons performed with analysis of variance and Scheffe's post hoc test for parametric data, and Kruskal-Wallis and Mann-Whitney $U$ test for non-parametric data. †Teachers' report was missing for 11 VLBW, eight SGA, and 11 control adolescents.

ADHD rating scale IV, Attention deficit hyperactivity disorder rating scale $\mathrm{IV}^{32}{ }^{33}$; $\mathrm{ASSQ}$, autism spectrum screening questionnaire ${ }^{31}$; CGAS, children's global assessment scale ${ }^{30} ; \mathrm{VLBW}$, very low birth weight; SGA, small for gestational age.
Thus, the non-significant differences found between SGA and controls may be underestimates of the real differences.

The results were mainly unchanged when we excluded the adolescents with low $\mathrm{IQ}_{\text {est }}$. Moreover, the increased risk of psychiatric symptoms among VLBW adolescents persisted after possible psychosocial confounders had been controlled for.

Table 4 Odds ratio (OR) with 95\% confidence intervals (Cl) as an estimate of the relative risk of psychiatric symptoms in two groups of low birthweight adolescents compared with a control group at 14 years of age, adjusted for psychosocial factors: psychiatric symptoms $\geqslant 75 \%$ of diagnostic criteria any disorder

\begin{tabular}{|c|c|c|c|c|}
\hline & \multicolumn{2}{|c|}{$\begin{array}{l}\text { VLBW } v \text { control } \\
(n=139)\end{array}$} & \multicolumn{2}{|c|}{$\begin{array}{l}\text { SGA } v \text { control } \\
(n=143)\end{array}$} \\
\hline & OR & $95 \% \mathrm{Cl}$ & OR & $95 \% \mathrm{Cl}$ \\
\hline Unadjusted OR & 5.7 & 2.5 to 13.0 & 2.0 & 0.8 to 4.8 \\
\hline \multicolumn{5}{|l|}{ Adjusted for: } \\
\hline \multicolumn{5}{|l|}{ Maternal } \\
\hline Age & 5.6 & 2.4 to 12.9 & 1.8 & 0.7 to 4.4 \\
\hline Education & 5.5 & 2.4 to 12.5 & 1.8 & 0.7 to 4.4 \\
\hline Mental health $\dagger$ & 7.1 & 2.7 to 18.8 & 2.1 & 0.8 to 5.4 \\
\hline \multicolumn{5}{|l|}{ Paternal } \\
\hline Age & 5.6 & 2.4 to 12.8 & 2.1 & 0.9 to 5.1 \\
\hline Education & 5.0 & 2.2 to 11.8 & 1.9 & 0.8 to 4.6 \\
\hline Mental health $\ddagger$ & 4.7 & 1.8 to 12.4 & 3.1 & 1.1 to 8.6 \\
\hline Socioeconomic status§ & 6.2 & 2.6 to 14.4 & 1.8 & 0.7 to 4.4 \\
\hline Monthly income & 6.0 & 2.5 to 14.2 & 1.9 & 0.8 to 4.8 \\
\hline Single parent & 5.6 & 2.5 to 12.9 & 2.0 & 0.8 to 4.8 \\
\hline
\end{tabular}

Bivariate logistic regression analysis displaying adjusted OR for possible confounding factors.

†Global severity index on symptom checklist-90- $\mathrm{R}^{34}$ was missing for six VLBW, one SGA, and nine control adolescents.

†Global severity index on symptom checklist-90- $\mathrm{R}^{34}$ was missing for 10 VLBW, six SGA, and 15 control adolescents.

$\S$ Hollingshead's two factor index of social position. ${ }^{37}$

VLBW, very low birth weight; SGA, small for gestational age. 
Our results on psychiatric symptoms are consistent with other studies on VLBW adolescents at ages 10-14 years. ${ }^{45151839}$ Prevalence reports on psychiatric disorders vary from $24 \%$ to $32 \%$, which is well in keeping with our results. $^{5} 1539$

The prevalence of anxiety disorders corresponds to reports of $8-10 \%$ in VLBW and LBW (birth weight $<2500 \mathrm{~g}$, ages 6-12). ${ }^{519} 40$ We did not find an increased prevalence of depression, which has been reported in one study of adolescents with birth weight $\leqslant 1000 \mathrm{~g}^{20}$

Our finding that $25 \%$ of VLBW adolescents had considerable attention deficit symptoms is in keeping with other studies. ${ }^{3}$ Reports on the prevalence of ADHD vary between $5 \%$ and $32 \%,{ }^{5} 1518193941-43$ presumably because of differences in study design, inclusion criteria, assessment age, and methods. We found that only $7 \%$ had ADHD according to DSM-IV criteria. This supports the minority of researchers who claim a low prevalence of ADHD in adolescence. ${ }^{15}{ }^{18} 41$ The male predominance described in children with $\mathrm{ADHD}^{44}$ was not found in the VLBW group, nor did they have conduct disorders. This is consistent with several reports in which the authors argue that VLBW children have a specific ("pure") form of ADHD with a dominating neurological cause..$^{5} 65$

We found autistic spectrum symptoms in the VLBW group. Studies on autism include pregnancy complications and intrauterine growth retardation as risk events, but the main conclusion is that there is a strong genetic component in the cause of autism. ${ }^{46-48}$ Few follow up studies of VLBW children have reported on autistic spectrum symptoms, ${ }^{19}{ }^{49}$ although there are reports on deficits in social skills. ${ }^{18}{ }^{19}{ }^{50}$ Sykes et al ${ }^{50}$ suggested that VLBW children have problems adjusting to the social environment, because of a failure in self regulatory functions. This hypothesis is further elaborated by Davis and Burns. ${ }^{51}$ Hille et al ${ }^{52}$ argued that the attention deficit may cause difficulties in social relations through poor processing of cognitive stimuli. We speculate that the core point may be specific problems in relating to other people, with deficits in comprehending the subtle clues of social relations, comprising both emotional and cognitive components.

In this study, we found an association between VLBW and psychiatric problems that could not be explained by socioeconomic status or the parents' mental health. A biological cause-effect relation seems plausible, as these children are born with immature brains and a high risk of damaging incidents in the neonatal period. ${ }^{568164043455253}$ To be born SGA at term seems to involve less biological risk of psychiatric problems. ${ }^{13}$ We also recognise that psychosocial experiences may interact with the biological vulnerability, as reported in other studies. ${ }^{4}{ }^{13}{ }^{54}$ Regardless of the cause, our results should draw attention to the fact that VLBW children may need long term health services.

In conclusion, we found that VLBW, but not SGA adolescents, have a high risk of developing psychiatric symptoms and disorders by the age of 14, especially attention deficit, anxiety, and relational problems affecting their social skills.

\section{ACKNOWLEDGEMENTS}

We thank the teenagers themselves, their parents and teachers for their cooperation and interest in the study. We also thank the child and adolescent psychiatrists Mari Jordet Bruheim and Sigrun Opsal Vilsvik for performing interviews and diagnostic reassessment work, physiotherapist Kari Anne I Evensen for assistance with the manuscript, and paediatrician Jon Skranes for valuable research advice.

\section{Authors' affiliations}

M S Indredavik, Department of Neuroscience, Norwegian University of Science and Technology, Trondheim, Norway
T Vik, Department of Community Medicine and General Practice, Norwegian University of Science and Technology

S Heyerdahl, Regional Centre for Child and Adolescent Psychiatry, Oslo, Norway

S Kulseng, A-M Brubakk, Department of Laboratory Medicine,

Children's and Women's Health, Norwegian University of Science and Technology

P Fayers, Unit for applied Clinical Research, Norwegian University of Science and Technology and Institute of Applied Health Sciences, University of Aberdeen, UK

Department of Child and Adolescent Psychiatry, Norwegian University of Science and Technology supported this study.

\section{REFERENCES}

1 Escobar GJ, Littenberg B, Petitti DB. Outcome among surviving very low birthweight infants: a meta-analysis. Arch Dis Child 1991;66:204-11.

2 McCormick MC. The outcomes of very low birth weight infants: are we asking the right questions? Pediatrics 1997;99:869-75.

3 Bhutta AT, Cleves MA, Casey PH, et al. Cognitive and behavioral outcomes of school-aged children who were born preterm. JAMA 2002;288:728-37.

4 Levy-Shiff R, Einat G, Har-Even D, et al. Emotional and behavioral adjustment in children born prematurely. J Clin Child Psychol 1994;23:323-33.

5 Botting N, Powls A, Cooke RWI. Attention deficit hyperactivity disorders and other psychiatric outcomes in very low birthweight children at 12 years. J Child Psychol Psychiatry 1997;38:931-41.

6 Wolke D. Psychological development of prematurely born children. Arch Dis Child 1998;78:567-70.

7 Zubrick SR, Kurinczuk JJ, McDermott BMC, et al. Fetal growth and subsequent mental health problems in children aged 4 to 13 years. Dev Med Child Neurol 2000;42:14-20.

8 Lou HC. Etiology and pathogenesis of Attention-deficit Hyperactivity Disorder (ADHD): significance of prematurity and perinatal hypoxic-haemodynamic encephalopathy. Acta Paediatr 1996:85:1266-71.

9 Horwood LJ, Mogridge N, Darlow BA. Cognitive, educational, and behavioural outcomes at 7 to 8 years in a national very low birthweight cohort. Arch Dis Child Fetal Neonatal Ed 1998;79:F12-20.

10 Vik T. Growth, morbidity, and psychomotor development in infants who were growth retarded in utero. Monograph. Trondheim: Norwegian University of Science and Tehnology, 1996.

11 Goldenberg RL, Hoffman HJ, Cliver SP. Neurodevelopmental outcome of small-for-gestational-age infants. Eur J Clin Nutr 1998;52:S54-8.

12 Westwood M, Kramer MS, Munz D, et al. Growth and development of fullterm nonasphyxiated small-for-gestational-age newborns: follow-up through adolescence. Pediatrics 1983;71:376-82.

13 Hack $M$. Effects of intrauterine growth retardation on mental performance and behavior, outcomes during adolescence and adulthood. Eur J Clin Nutr 1998;52(suppl 1):S65-71.

14 Grantham-McGregor SM. Small for gestational age, term babies, in the first six years of life. Eur J Clin Nutr 1998;52(suppl 1):S59-64.

15 Stevenson CJ, Blackburn P, Pharoah POD. Longitudinal study of behaviour disorders in low birthweight infants. Arch Dis Child Fetal Neonatal Ed 1999;81:F5-9.

16 Stewart AL, Rifkin L, Amess PN, et al. Brain structure and neurocognitive and behavioural function in adolescents who were born very preterm. Lancet 1999:353:1653-7.

17 Breslau N, Chilcoat HD. Psychiatric sequelae of low birth weight at 11 years of age. Biol Psychiatry 2000;47:1005-11

18 Rickards AL, Kelly EA, Doyle LW, et al. Cognition, academic progress, behavior and self-concept at 14 years of very low birth weight children. J Dev Behav Pediatr 2001;22:11-18.

19 Elgen I, Sommerfelt K, Markestad T. Population based, controlled study of behavioural problems and psychiatric disorders in low birthweight children at 11 years of age. Arch Dis Child Fetal Neonatal Ed 2002;87:F128-32.

20 Saigal S, Pinelli J, Hoult L, et al. Psychopathology and social competencies of adolescents who were extremely low birth weight. Pediatrics 2003;111:969-75

21 Skranes JS, Vik T, Nilsen G, et al. Cerebral magnetic resonance imaging and mental and motor function of very low birth weight children at six years of age. Neuropediatrics 1997:28:1-7.

22 Skranes J, Nilsen G, Smevik O, et al. Cerebral MRI of very low birth weight children at 6 years of age compared with the findings at 1 year. Pediatr Radiol 1998;28:471-5.

23 Skranes J, Vik T, Nilsen G, et al. Can cerebral MRI at age 1 predict motor and intellectual outcomes in very-low-birthweight children? Dev Med Child Neurol 1998;40:256-62

24 Bakketeig LS, Jacobsen G, Hoffman HJ, et al. Pre-pregnancy risk factors of small-for-gestational age births among parous women in Scandinavia. Acto Obstet Gynecol Scand 1993;72:273-9.

25 Vik T, Markestad T, Ahlsten G, et al. Body proportions and early neonatal morbidity in small for gestational age infants of successive births. Acta Obstet Gynecol Scand 1997;76(Suppl):80-5

26 Vik T, Jacobsen G, Vatten L, et al. Pre- and post-natal growth in children of women who smoked in pregnancy. Early Hum Dev 1996;45:245-55.

27 Kaufman J, Birmaher B, Brent D, et al. Schedule for affective disorders and schizophrenia for school-aged children-present and lifetime version (K-SADS$\mathrm{PL})$ : initial reliability and validity data. J Am Acad Child Adolesc Psychiatry 1997;38:1065-9. 
28 Ambrosini PJ. Historical development and present status of the schedule for affective disorders and schizophrenia for school-age children (K-SADS). J Am Acad Child Adolesc Psychiatry 2000;39:49-58.

29 American Psychiatric Association. Diagnostic and statistical manual of mental disorders, 4th ed, text revision. Washington, DC: American Psychiatric Association, 2000.

30 Shaffer D, Gould MS, Brasic J, et al. A Children's Global Assessment Scale (CGAS) (for children 4 to 16 years of age). Psychopharmacol Bull 1985;21:747-8.

31 Ehlers S, Gillberg C, Wing L. A screening questionnaire for Asperger syndrome and other high-functioning autism spectrum disorders in school age children. J Autism Dev Disord 1999;29:129-41.

32 Barkley RA, Murphy K. Attention deficit hyperactivity disorder: a clinical workbook. New York: Guilford Press, 1998.

33 Kvilhaug G, et al. AD/HD Et verktøy for kartlegging av barn og ungdom. Oslo: Novus Forlag, 1998

34 Derogatis LR. Symptom Checklist-90-R. Administration, scoring, and procedures manual. Minneapolis: NCS Pearson Inc, 1994

35 Wechsler D. Wechsler intelligence scale for children-third edition. Manual. Stockholm: Psykologiförlaget AB, 1999.

36 Kaufman AS. Attacking subtest profiles: illustrations and applications. Intelligent testing with the WISC-R. New York: John Wiley \& Sons, 1979.

37 Hollingshead AB. Two factor index of social position. New Haven, CT: Yale University, 1958.

38 Rosner B. Fundamental of biostatistics, 5th ed. Duxbury: Thomson Learning, 2000.

39 Stjernqvist K, Svenningsen NW. Ten-year follow-up of children born before 29 gestational weeks: health, cognitive development, behaviour and school achievement. Acta Paediatr 1999;88:557-62.

40 Whitaker AH, Van Rossem R, Feldman JF, et al. Psychiatric outcomes in low birth-weight children at age 6 years: relation to neonatal cranial ultrasound abnormalities. Arch Gen Psychiatry 1997;54:847-56.
41 Taylor HG, Klein N, Minich NM, et al. Middle-school-age outcomes in children with very low birthweight. Child Dev 2000;71:1495-511.

42 Pharoah POD, Stevenson CJ, Cooke RWI, et al. Prevalence of behaviour disorders in low birthweight infants. Arch Dis Child 1994:70:271-4.

43 Breslau N, Brown GG, DelDotto JE, et al. Psychiatric sequelae of low birth weight at 6 years of age. J Abnorm Child Psychol 1996;24:385-400.

44 Graham P, Turk J, Verhulst F. Child psychiatry. A developmental approach $3^{\text {rd }}$ ed. Oxford: Oxford University Press, 1999

45 Szatmari P, Saigal S, Rosenbaum P, et al. Psychopathology and adaptive functioning among extremely low birthweight children at eight years of age. Dev Psychopathol 1993;5:345-57

46 Wilkerson DS, Volpe AG, Dean RS, et al. Perinatal complications as predictors of infantile autism. Int J Neurosci 2002;112:1085-98.

47 Hultman CM, Sparén P, Cnattingius S. Perinatal risk factors for infantile autism. Epidemiology 2002;13:417-23.

48 Zwaigenbaum L, Szatmari P, Jones MB, et al. Pregnancy and birth complications in autism and liability to the broader autism phenotype. J Am Acad Child Adolesc Psychiatry 2002:41:572-9.

49 Halsey CL, Collin MF, Anderson CL. Extremely low-birth-weight children and their peers. Arch Pediatr Adolesc Med 1996;150:790-4.

50 Sykes DH, Hoy EA, Bill JM, et al. Behavioural adjustment in school of very low birthweight children. J Child Psychol Psychiatry 1997;38:315-25.

51 Davis DW, Burns B. Problems of self-regulation: a new way to view deficits in children born prematurely. Issues Ment Health Nurs 2001;22:305-23.

52 Hille ETM, den Ouden AL, Saigal S, et al. Behavioural problems in children who weigh $1000 \mathrm{~g}$ or less at birth in four countries. Lancet 2001;357:1641-3.

53 Castellanos FX. Toward a pathophysiology of attention-deficit/hyperactivity disorder. Clin Pediatr 1997 Jul:381-93.

54 Levy-Shiff R, Einat G, Mogilner MB, et al. Biological and environmental correlates of developmental outcome of prematurely born infants in early adolescence. J Pediatr Psychol 1994;19:63-78. 